SISTEMA
ELETRONNICO
DE REVISTAS
SER I UFPR

\title{
Navegando pelos mares da controvérsia política: a Inspetoria da Pesca e os primeiros estudos sobre o plâncton no Brasil (1913-1915)
}

\section{Sailing through political controversies seas: Inspetoria da Pesca and the first studies about plankton in Brazil (1913-1915)}

\author{
Andre Vasques VITAL ${ }^{1 *}$, Cristiane Gomes BARRETO² \\ ${ }^{1}$ Centro Universitário de Anápolis (UniEVANGELICA), Anápolis, GO, Brasil. \\ ${ }^{2}$ Centro de Desenvolvimento Sustentável (CDS), Universidade de Brasília (UNB), Brasília, DF, Brasil. \\ *E-mail de contato: vasques_vital@tutanota.com
}

Ensaio recebido em 26 de maio de 2017, versão final aceita em 17 de agosto de 2018.

\begin{abstract}
RESUMO: O ensaio analisa a formação, a atuação e as controvérsias políticas em torno da Inspetoria da Pesca, instituição que funcionou como um órgão subordinado ao Ministério da Agricultura, Indústria e Comércio (MAIC), entre os anos de 1913 e 1915. Vista pelo MAIC como uma importante iniciativa para o incentivo do desenvolvimento da indústria pesqueira no Brasil, a Inspetoria foi alvo de críticas no Congresso Nacional e utilizada por jornais de oposição ao Executivo Federal para ataques ao então Presidente Hermes da Fonseca (1910-1914). Por outro lado, um fenômeno causando grande mortandade de peixes na Baía de Guanabara atraiu forte atenção dos cientistas que compunham esse órgão, resultando nos primeiros investimentos em pesquisas sobre o plâncton no Brasil. A presente análise, assim, foi possível a partir de pesquisa documental em relatórios do MAIC, artigos científicos e manifestações diversas na imprensa carioca do período. Esta pesquisa sugere que, apesar das críticas sofridas na época e sua efêmera existência, a Inspetoria da Pesca teve um impacto importante nos primórdios da planctologia no Brasil.
\end{abstract}

Palavras-chave: oceanografia; planctologia; Ministério da Agricultura, Indústria e Comércio; Inspetoria da Pesca.

ABSTRACT: This manuscript analyzes the formation, the action and political controversies around the Inspetoria da Pesca (Brazilian Fisheries Agency), that was an accessorial agency of the Ministry of Agriculture, Industry and Commerce (MAIC) between 1913 to 1915. Considered as an important initiative to encourage the development of the fishing industry in Brazil, the agency was criticized in the National Congress and used by newspapers opposing the Federal Executive to attack the then President Hermes da Fonseca (1910-1914). On the other hand, 
a phenomenon that caused a great fish mortality in Guanabara Bay attracted strong attention from the agency's scientists. This circumstance culminated in the first Brazilian investments in plankton research. This analysis was based on data from documental research of MAIC reports, scientific articles and diverse manifestations in the Carioca press of that period. Despite the criticisms suffered at the time and its ephemeral existence, this research suggests that the Fisheries Agency had an important impact in the beginnings of Planktology in Brazil.

Keywords: oceanography; planktology; Ministério da Agricultura, Indústria e Comércio; Fisheries Agency.

\section{Introdução}

A curiosidade pelas criaturas marinhas e pelos mistérios dos oceanos são quase tão antigas quanto o evento da expansão da humanidade pelos continentes. Essa curiosidade pode ser observada, por exemplo, em Aristóteles (384-322 A.C.), no tratado Historia Animalium, que conta com densas descrições de variadas formas de vida marinha. Um dos primeiros estudos baseados em preceitos da ciência moderna sobre os componentes físicos e bióticos dos oceanos, por sua vez, foi lançado em 1725, quando o naturalista italiano Luigi Marsigli (1658-1730) publicou Histoire Physique de la Mer (Deacon, 1971, p. 445).

No Brasil, as primeiras pesquisas oceanográficas ocorreram durante a expedição do Navio Beagle (1831-1836), que contou com a presença do naturalista Charles Darwin. Além de resultar na publicação da obra On The Origin of Species (A Origem das Espécies), essa expedição proporcionou a elaboração de artigos sobre arrecifes de arenito em Pernambuco, arrecifes de coral, cracas e sobre a origem dos atóis. Outras expedições estrangeiras passaram pelo Brasil no século XIX, como a austríaca Novara Expedition (1865), a americana Hassler Expedition (1872) e a britânica Challenger
Expedition (1872-1876), esta última resultando na classificação de mais de 4.700 espécies da vida marinha (Brunner, 2005, p. 14). A visita dessas grandes expedições à costa brasileira justificava-se pelo potencial científico que ela oferecia, tanto por ser uma das costas mais extensas do mundo, quanto pelos escassos estudos de história natural conduzidos nessa área (Grohmann et al., 2016).

Durante as expedições do navio Beagle, diversos organismos microscópicos foram coletados e classificados. Esses micro-organismos tinham em comum o modo de vida à deriva e disperso no ambiente aquático, com pouca ou nenhuma capacidade de locomoção própria. Em 1887, o zoólogo alemão Victor Hensen (1835-1924) propôs o nome "plankton", do grego plagktós (errante, vagabundo) para esses seres (Sardet, 2015, p. 18). Dois anos depois, Hensen liderava a Plankton Expedition (1889), que coletou mais desses micro-organismos no mar do Caribe e na foz dos rios Amazonas e Tocantins (Damkaer \& Mrozek-Dahl, 1980, p. 462-473). Esses foram os primórdios da planctologia como uma especialidade da oceanografia.

$\mathrm{O}$ interesse brasileiro na oceanografia se iniciou com a pretensão de desenvolver a navegação de cabotagem e de defesa costeira. O primeiro passo nesse sentido foi a criação, em 1852, da Companhia 
Hidrográfica da Marinha do Brasil, responsável pelo mapeamento batimétrico, elaboração de cartas náuticas e demais atribuições ligadas à navegação. Em 1876, foi criada a Repartição Hidrográfica do Ministério da Marinha, que em 1924 passou a se chamar Diretoria de Hidrografia e Navegação (Archela \& Archela, 2008). Mas somente em 1933 publicou-se a primeira carta hidrográfica costeira nacional, com o auxílio de equipamentos e técnicas modernizadas (Paiva, 1996, p. 463). A oceanografia, contudo, só ganharia ímpeto com a criação do Instituto Paulista de Oceanografia, em 1946, que é admitido na comunidade científica como um marco nacional na investigação da fauna, da flora, dos minérios e no mapeamento do potencial energético marinho da costa brasileira (Varela, 2014).

No entanto, entre a existência da Repartição Hidrográfica e da Diretoria de Hidrografia e Navegação, registra-se uma instituição efêmera, eclipsada pelos (des)interesses políticos da época, mas que faz parte dessa história e representa a primeira iniciativa de institucionalização da pesquisa oceanográfica brasileira - a Inspetoria de Pesca. Com a pretensão de garantir "a organização dos serviços de pesca" no Brasil, o zoólogo Alípio de Miranda Ribeiro foi indicado como pessoa à frente da Inspetoria, que era parte do então Ministério da Agricultura, Indústria e Comércio (MAIC).

O ensaio analisa a formação e a atuação da Inspetoria da Pesca entre os anos de 1913 e 1915. Instituição pensada com a finalidade de organizar e incentivar a indústria pesqueira, a Inspetoria se destacou pelas pesquisas zoológicas em torno dos micro-organismos planctônicos da Baía de Guanabara, conformando uma agenda de pesquisas que permaneceu mesmo com o fim desse órgão. Até o momento, poucos estudos citam a existência da Ins- petoria da Pesca, sem, todavia, aprofundar qualquer análise sobre essa instituição (Pombal Jr., 2002; Gomes et al., 2012; Vital \& Tejerina-Garro, 2018). Por outro lado, tem crescido nos últimos anos o número de trabalhos dedicados à história da oceanografia, com ênfase, por exemplo, em trajetórias científicas (Lopes \& Podgorny, 2014), na importância da fotografia e das aquarelas na ciência oceanográfica (Shick, 2008; Jardim et al., 2014; Martínez, 2014), na produção e difusão dos aquários para pesquisas e ensino de biologia marinha (Carpine-Lancre, 1994; Kisling Jr., 2000; Brunner, 2005; Salgado \& Marandino, 2014) e institucionalização da oceanografia (Varela, 2014; Longo \& Amado Filho, 2014; García, 2014; Rollo et al., 2014).

Aqui a ênfase será dada à Inspetoria da Pesca enquanto instituição científica e de incremento à pesca comercial, destacando, ao mesmo tempo, a trajetória de alguns de seus membros, em especial o médico José Gomes de Faria, responsável pelo gabinete de zoologia e pelos estudos sobre plâncton na Baía de Guanabara. Serão exploradas também as relações entre a ocorrência de fenômenos não-humanos e o desenvolvimento institucional e a consolidação científica da planctologia no Brasil.

Ao longo do ensaio, é dada especial atenção às contingências de ordem política, econômica e ambiental que afetaram a existência institucional da Inspetoria da Pesca e às escolhas feitas pelos seus membros. Assim, as principais fontes são os relatórios do MAIC, para analisar a emergência e funcionamento do órgão; o Boletim do Ministério da Agricultura, Indústria e Comércio, que mapeia os meandros do funcionamento do órgão e possíveis respostas aos críticos na imprensa; os principais órgãos da imprensa carioca, que relatam os debates no Congresso Nacional, as polêmicas e controvérsias 
envolvendo os trabalhos da Inspetoria; e, por fim, trabalhos científicos produzidos no Brasil sobre plâncton, nas décadas de 1910 e 1920 , especialmente de autoria de membros da Inspetoria.

\section{O Ministério da Agricultura, Indústria e Comércio e a criação da Inspetoria da Pesca}

O Ministério da Agricultura, Indústria e Comércio (MAIC) foi criado em 1906, por iniciativa da Sociedade Nacional de Agricultura (SNA), sendo regulamentado em 1909. A SNA, entretanto, existia desde 1897, congregando produtores rurais de vários estados. As suas atividades estavam voltadas para a produção de um mercado interno no País, desvinculados do expressivo setor cafeeiro. Os membros da SNA acreditavam que o problema do atraso econômico do Brasil estaria especialmente atrelado a um modelo predominantemente exportador, baseado na monocultura e no extrativismo, como era o caso do café e da borracha, produtos que lideravam as exportações brasileiras na época. Dessa forma, tanto as políticas, quanto as publicações oficiais da SNA e do MAIC, à época, incentivavam a diversificação da produção agrícola, o conhecimento sistemático da flora e fauna nacionais e o que se denominava "uso racional dos recursos naturais". Esse "uso racional" estaria ligado a formas de exploração econômica de solos, florestas, águas e animais de modo a potencializar os ganhos e, concomitantemente, não empreender devastações em larga escala que comprometessem a futura continuidade de tais atividades (Bhering \& Maio, 2011; Mello, 2012). A criação da Inspetoria da Pesca no âmbito do MAIC é, assim, uma outra dimensão da atuação desse ministério envolvendo a promoção de incentivos e regras na exploração econômica do ambiente aquático.

No relatório do MAIC de 1911, dirigido ao Presidente Hermes da Fonseca, o então ministro Pedro de Toledo ressaltou a necessidade de estudos sistemáticos sobre a fauna e as condições de vida das espécies marinhas do litoral brasileiro para o incremento da exploração pesqueira ${ }^{1}$. Para ele, era necessário conhecer os hábitos, condições de vida, época e idade de procriação, além dos lugares de desova dos peixes alvos de exploração econômica. Somente assim seria possível construir as bases da regulamentação e do incentivo da pesca no Brasil (Brasil, 1911, p. 204).

Toledo exemplificou o fracasso da Bandeira, Bravo \& Companhia, uma grande organização pesqueira que atuava no litoral do Rio de Janeiro, e as más condições de vida e sustento dos pescadores como indicativo das necessidades desses estudos. Essa empresa iniciou as operações de pesca de arrasto em larga escala entre São Paulo e Cabo Frio, no Rio de Janeiro, em janeiro 1903, com o barco a vapor Annie e sob o comando de um perito alemão, com grande experiência no litoral da Alemanha. $\mathrm{O}$ dito perito fracassou em interpretar as sondagens feitas pela empresa a partir do referencial que tinha dos mares do norte da Europa. A qualidade dos

\footnotetext{
${ }^{1}$ Importante destacar que a preocupação com um estudo sistemático da fauna marinha brasileira para a sua exploração econômica encontra paralelo com o que Lima (1999) e Sá et al., (2008) chamam de "Missões Civilizatórias" da Primeira República, que ocorreram na década de 1910, ou seja, concomitantemente à formação de uma Inspetoria da Pesca. Essas missões tinham por objetivo realizar obras de infraestrutura para a integração física do território nacional e, sobretudo, produzir conhecimentos científicos sobre a fauna, a flora, os minérios e as condições de vida no interior do Brasil, de modo a propor formas de incorporar economicamente essas regiões ao sistema produtivo nacional.
} 
peixes capturados se mostrou muito inferior ao que era esperado, levando à suspensão das operações e à dissolução da empresa com apenas três meses de existência. Por outro lado, segundo o ministro da agricultura, os pescadores autônomos do litoral carioca e fluminense trabalhavam em condições precárias, mantendo relações com negociantes que adiantavam somas financeiras em troca do produto da pesca que, geralmente, era de qualidade inferior e não cobria as suas dívidas, criando um laço de dependência econômica (Brasil, 1911, p. 204).

Apesar de o ministro Pedro de Toledo admitir que naquele momento atuavam outras empresas pesqueiras no Paraná, São Paulo e Rio de Janeiro, com algum sucesso, ele apontou para a urgência da criação de um órgão, uma Inspetoria da Pesca. A inspetoria ficaria sob o controle do MAIC e dedicada exclusivamente ao incentivo da atividade pesqueira em território nacional. Dentre os principais objetivos desse órgão estavam: 1) a promoção de auxílio e instrução aos pescadores autônomos; 2) o incentivo à piscicultura, povoando as águas doces e salgadas do território nacional com espécies nativas e exóticas de maior valor comercial; 3) a realização de inquéritos sobre as condições de vida, costumes dos pescadores e o estado da economia pesqueira; e 4) o mapeamento do ciclo de vida e dos hábitos das espécies de quelônios, peixes, crustáceos e moluscos "mais apreciados". Esses dados, segundo o ministro, seriam importantes para organizar um projeto de regulamento da pesca e sua fiscalização, de modo a "coibir os grandes e criminosos abusos que se praticam e que concorrem para o despovoamento de águas piscosas" (Brasil, 1911, p. 205). Dentre outras finalidades, a Inspetoria da Pesca deveria organizar cooperativas de pescadores, realizar o levantamento da carta batimétrica ${ }^{2}$ da costa e organizar um museu de aparelhos, cartas de pesca e de coleções de espécies da fauna marítima, lacustre e fluvial, que fosse instrutivo e acessível aos visitantes.

A proposta era criar também um conjunto de distritos e estações de pesca, formando colônias de pescadores próximas às estações. Nesses distritos e estações, seriam oferecidos cursos de habilitação aos pescadores com ensino de prática de navegação à vela e a vapor, manejo de aparelhos de pesca, salga e preparo de peixes em conservas, produção de adubo com restos do pescado, piscicultura e ostreicultura. Para as empresas, a Inspetoria poderia dar concessões de mares, terras públicas e uma série de isenções fiscais à importação, desde aparelhos e ferramentas de manutenção de equipamentos de pesca, embarcações e material de preparo de conservas. A ideia era incentivar a indústria pesqueira em nível nacional (Brasil, 1911, p. 205).

Um dos maiores problemas apontados, relativo à pesca e ao consumo de pescado no Brasil, nesse período, era a balança comercial muito desfavorável para o País, devido à importação maciça de frutos do mar, especialmente o bacalhau e os peixes em conserva. Estima-se que, entre 1910 e 1915, a importação de bacalhau tenha variado entre 33 e 49 mil toneladas, enquanto a importação de peixe em conserva tenha variado entre os patamares de 1,3 mil e 3,8 mil toneladas, representando um volume de importação que ultrapassava a casa dos 20 mil contos de réis (Costa, 1916). Essa situação era vista

\footnotetext{
${ }^{2}$ Carta batimétrica guarda relação com a profundidade dos oceanos em associação com a posição de uma embarcação na superfície da água. O conjunto desses dados podem ser representados cartograficamente.
} 
como absurda por alguns autores da época, que ressaltavam a riqueza da fauna marinha e fluvial do Brasil, pouco explorada do ponto de vista econômi$\mathrm{co}^{3}$. Em períodos anteriores, houve iniciativas para incentivar o desenvolvimento da indústria pesqueira do Brasil. Em 1856, por exemplo, o legislativo imperial aprovou uma lei autorizando uma série de favores, garantias e privilégios para empresas de pesca, salga e seca de peixes que atuassem no litoral e nos rios do País. Essa lei foi regulamentada pelo decreto $\mathrm{n}^{\circ} 8.338$ de 17 de dezembro de 1891 , mas permaneceu apenas no campo das intenções, tornando-se letra morta (Costa, 1916, p. 97). Assim, a proposta do ministro Pedro de Toledo representava a terceira tentativa governamental em incentivar a indústria pesqueira em nível nacional.

Em 4 de janeiro de 1912, a Câmara aprovou a requisição do ministro Pedro de Toledo e autorizou, com o artigo 73 da lei orçamentária $n^{\circ} 2.544$, a criação do órgão de incentivo à indústria pesqueira no âmbito do MAIC. Em 17 de julho de 1912, o então Presidente Hermes da Fonseca expediu o decreto $\mathrm{n}^{\circ}$ 9.672, criando a Inspetoria da Pesca e o seu respectivo regulamento. O principal objetivo da Inspetoria da Pesca era "estudar os recursos naturais das águas brasileiras, divulgá-los tanto quanto possível e regular a sua utilização" (Brasil, 1912, p. 173). A sede da Inspetoria foi instalada na Capital Federal e dotada de laboratório de aquicultura, gabinetes de zoologia, botânica, física, química, fotografia, microfotografia e desenho, além de um museu para expor espécimes, produtos industriais marinhos, instrumentos de aquicultura, mapas, fotografias, trabalhos científicos produzidos pelos gabinetes, etc. A sede também foi dotada de um escritório para o expediente e contabilidade da inspetoria e uma biblioteca com livros e revistas sobre assuntos aquícolas (Brasil, 1912, p. 173).

Era prerrogativa da Inspetoria publicar um anuário em francês, inglês e português contendo estudos e as respectivas estampas de espécies coletadas. Além do anuário, deveria ser publicada uma revista ${ }^{4}$ contendo dados referentes à pesca, movimento industrial, cooperativas, estatísticas e cursos oferecidos pelas escolas sob a coordenação do órgão (Brasil, 1912, p. 174). Na própria sede da Inspetoria deveriam ser realizadas conferências e cursos destinados ao público geral e haver a recepção de pesquisadores estrangeiros interessados em realizar estudos no Brasil.

O decreto previa a fundação de estações de pesca após estudos prévios a serem realizados pela Inspetoria. Contudo, o texto final da lei já trazia a organização dos cursos preparatórios e complementares para os pescadores, com as matérias e avaliações a serem realizadas. Ficava a cargo da Inspetoria organizar cooperativas de pescadores e seguros marítimos. Em relação às empresas, o texto final possuía indicações idênticas às proposições do ministro Pedro de Toledo, prevendo também a subvenção de companhias pesqueiras que oferecessem cursos complementares de pesca. O registro de pescadores, que antes ficava a cargo do Ministério da Marinha, passava para o Ministério da Agricultura,

\footnotetext{
${ }^{3}$ Há alguns artigos no próprio Boletim do Ministério da Agricultura, Indústria e Comércio que apontam para o paradoxo do grande volume de importação de peixes, frente a riqueza da fauna aquática brasileira.

${ }^{4}$ Não foram encontradas referências à publicação do anuário e da revista ao longo dos anos de existência da Inspetoria da Pesca. É possível que esse plano não tenha sido concretizado.
} 
Indústria e Comércio, que definia a obrigatoriedade de sua renovação anual (Brasil, 1912, p. 175).

Por fim, o texto final lançava uma série de regulamentos e proibições. Ele proibia a pesca de arrastão por barcos a vapor no espaço de cinco milhas a partir da costa, o uso de dinamites ou substâncias venenosas, a captura de qualquer espécie 15 dias antes da procriação, a captura de alevinos, a atividade pesqueira em áreas poluídas e a extração de moluscos encontrados em cascos de navios banhados a cobre. O decreto regulava também o tamanho das redes usadas por pescadores e empresas, os horários da pesca e medidas outras, como a proibição do lançamento de resíduos tóxicos por particulares e empresas em rios, lagos e baías, o ancoramento de embarcações em bancos de ostras e mexilhões e a obstrução de canais, rios e lagos por aparelhos de pesca (Brasil, 1912, p. 176). Estudos e fiscalizações deveriam ser realizados por meio de embarcações que seriam adquiridas pelo Governo Federal.

$\mathrm{O}$ decreto, em tese, era destinado a regular a pesca em todo o território nacional. Mas o próprio texto final deixava claro em suas últimas linhas que "para o exercício da pesca nas águas de jurisdição dos estados e municipalidades, a União promoverá acordo com os respectivos governos" (Brasil, 1912, p. 176). Para que a Inspetoria da Pesca pudesse atuar além da Capital Federal, era necessária a anuência dos governos estaduais.

Inicialmente, foram planejadas três estações de pesca: a primeira com sede na cidade de São Luiz do Maranhão, a segunda na Capital Federal e a terceira na cidade de Rio Grande, no Rio Grande do Sul. As estações do Rio Grande e da Capital Federal foram inauguradas, mas os registros e a fiscalização da pesca se concentraram principalmente nas águas desta última localidade, e mesmo assim com grande dificuldade devido ao reduzido número de fiscais. Havia também a dificuldade de punir os infratores, pela falta de uma lei penal específica para esses casos (Brasil, 1914, p. 107).

A Inspetoria da Pesca ficou sob o comando do naturalista Alípio de Miranda Ribeiro, da seção de zoologia do Museu Nacional. Entre os membros da Inspetoria estavam Gustavo Guimarães, como chefe do escritório; o médico José Gomes de Faria, no gabinete de zoologia; o botânico Francisco Carlos Hoehne, como chefe do gabinete de Botânica; o primeiro-tenente da armada, Evandro dos Santos, como perito de barcos; Mendes Vianna, no cargo de chefe da estação de pesca do Distrito Federal; e Heráclito Ribeiro de Castro, no cargo de professor da estação (Correio da Manhã, 15/02/1913). Foi esse o grupo que atuou até o último ano de existência da Inspetoria.

\section{A Inspetoria da Pesca entre plânctons e controvérsias políticas}

Apesar da autorização da Câmara e do Senado Federal, em janeiro de 1912, a atuação da Inspetoria da Pesca teve início somente com a sua organização de fato em maio de 1913, e a inauguração da primeira estação de pesca, a do Distrito Federal, em 12 de julho do mesmo ano (Correio da Manhã, 14/07/1913). Após a inauguração, os cientistas da Inspetoria iniciaram a importação de instrumentos para a realização das pesquisas e fizeram pequenas viagens para estudos na Baía de Guanabara. Foi justamente nos últimos dias do mês de julho que um evento chamaria a atenção do Governo Federal, da imprensa e mesmo da comunidade médica para atuação da Inspetoria. 
Durante uma pesquisa de campo realizada pelo Dr. Gomes de Faria, ele e os membros da estação de pesca notaram que as águas do mar apresentavam uma cor vermelho ferrugem na área entre o Cais do Porto e a área de São Cristóvão. A intensidade do fenômeno, e as informações dadas por pescadores sobre o aparecimento de grande número de peixes mortos, deixou a Inspetoria da Pesca em alerta (Faria, 1914, p. 29). Imediatamente, o então Ministro Pedro de Toledo foi notificado sobre a ocorrência de "uma epidemia produzida por um peridíneo" provocando a morte de peixes da Baía, hipótese defendida por Faria (Correio da Manhã, 03/08/1913). O titular da pasta da agricultura enviou um telegrama para o ministro do interior solicitando que a Diretoria Geral de Saúde Pública (DGSP) proibisse com urgência a venda de peixes que eram apanhados já mortos na Baía. Em $1^{\circ}$ de agosto, a Inspetoria da Pesca, em conjunto com a DGSP, proibiu temporariamente a pesca na região entre o "Cais dos Mineiros e a Ponta do Caju" ( $O$ Paíz, 04/08/1913). A medida só seria revogada 14 dias depois (Correio da Manhã, 14/08/1913).

A ação rápida dos pesquisadores da estação frente ao evento foi positiva para a imagem da Inspetoria da Pesca, dando ímpeto à reivindicação de maiores investimentos do MAIC para as pesquisas no mar. Para continuar os estudos, o gabinete de zoologia precisava de uma embarcação a ser usada exclusivamente nas pesquisas, além de material para coleta de peixes - e, principalmente, plânctons - de modo a investigar as manchas nas águas da Baía de Guanabara e seus efeitos na vida marinha. O mesmo fenômeno de fins de julho seria, tempos depois, verificado na região de Botafogo. Em 1914, José Gomes de Faria relatou que o evento era conhecido pelos pescadores como "água do monte" e atribuída por eles às águas doces que desciam ao mar após as chuvas. A explicação dos pescadores, contudo, era descartada pelo cientista como sendo o real motivo para as manchas (Faria, 1914, p. 38). Assim, o mistério das águas cor de ferrugem e dos peridíneos na Baía de Guanabara perdurava e animava o investimento em pesquisas no âmbito da Inspetoria.

Em setembro de 1913, o MAIC autorizou a aquisição de material em Londres para equipar o laboratório de zoologia da Inspetoria de Pesca e uma embarcação para expedições em alto mar (Correio da Manhã, 03/09/1913). Por 70 contos de réis, a pasta da agricultura adquiriu um iate especialmente destinado às pesquisas marítimas, batizado de "José Bonifácio", em homenagem ao naturalista José Bonifácio de Andrada e Silva (1763-1838), considerado um dos patriarcas da independência e um precursor da crítica ambiental brasileira (Correio da Manhã, 20/09/1913). O custo dessas aquisições chamou a atenção de políticos e da imprensa carioca, especialmente dos jornais que faziam oposição ao governo Hermes da Fonseca. Considerando exagerado o volume de investimentos para os estudos no mar, alguns jornais passaram a criticar e atacar esses gastos, visando, principalmente, a arranhar a imagem do então Presidente da República.

Antes mesmo do início da atuação da Inspetoria da Pesca, houve questionamentos por parte da imprensa sobre a viabilidade financeira do órgão pela maneira como foi estruturado. Um artigo publicado no Jornal do Commercio, de 31 de julho, levantava dúvidas sobre a robustez da inspetoria, dotada de cinco gabinetes, laboratório de ciências e ainda com a previsão de aquisição de embarcações, materiais para pesquisa e escolas, esquecendo a "precária situação do tesouro" nacional (Serviço 
de Informação e Divulgação, 1912). A edição de julho-agosto de 1912 do Boletim do Ministério da Agricultura, Indústria e Comércio, periódico do serviço de informações e divulgação desse ministério, publicou uma resposta ao artigo do Jornal do Commercio (Serviço de Informação e Divulgação, 1912). Essas críticas tomariam mais corpo em 1913, com a aquisição do iate José Bonifácio.

As críticas mais severas vieram do jornal Correio da Manhã , que fazia oposição ao governo Hermes da Fonseca. Houve um aproveitamento da polêmica em torno dos gastos com a Inspetoria da Pesca para lançar críticas diretas ao poder executivo. Em 20 de setembro de 1913, esse periódico lançou o artigo “Quem vai pescar no Iate José Bonifácio?", denunciando supostas irregularidades na compra da embarcação. Segundo a reportagem, o iate era de propriedade de um milionário norte-americano, o "sr. Benedict", ex-sócio da empresa The Amazon Wireless Telegraph que, naquela altura, movia uma ação contra o governo brasileiro pedindo indenização no valor de dois mil contos de réis, devido ao cancelamento da concessão de exploração da rede telegráfica na região Norte (Jornal do Commercio de Manáos, 16/05/1912). Concomitantemente à ação movida em território nacional, o empresário também havia feito uma reclamação formal junto à embaixada norte-americana, buscando pressionar o governo pela via diplomática. A reportagem indicava que a compra do iate poderia ser fruto de uma negociação visando à dissolução do processo e da representação contra o governo brasileiro. O advogado de Benedict era o então governador do Pará, Enéas Martins, que foi acusado de ter intermediado o diálogo e a aquisição da embarcação (Correio da Manhã, 20/09/1913).
A reportagem continha a denúncia de que o iate teria sido palco, no passado, de encontros entre Benedict e vários advogados e políticos brasileiros, incluindo o então Presidente Hermes da Fonseca. Esse fator justificava o luxo e a modernidade da embarcação: "É uma faca... - disse-nos pitorescamente, o mestre da lancha que nos levara até as águas em que se banha o Iate. - Aquilo corta o mar que nem navalha... há muito luxo lá dentro; isso espanta, patrão...” (Correio da Manhã, 20/09/1913). No entanto, o correspondente do jornal não conseguiu acesso ao interior do iate "o que sobremaneira nos contrariou por nos roubar o gozo de ver o luxo, e pasmar para as coisas que (dizem) fazem da airosa nave de três mastros um verdadeiro paraíso flutuante" (Correio da Manhã, 20/09/1913). Mesmo sem comprovar as informações obtidas sobre o conforto da embarcação, o artigo traz uma provocação direta ao Presidente da República: "Consta que o marechal Hermes fará no José Bonifácio a sua viagem de segundas núpcias", uma referência ao segundo casamento de Hermes da Fonseca com Nair de Tefé (Correio da Manhã, 20/09/1913).

Já em fins de 1913, tiveram início as controvérsias no seio da Câmara a respeito dos gastos do governo com a Inspetoria da Pesca. Essas controvérsias, em alguns casos, opuseram deputados do estado do Rio de Janeiro e do Distrito Federal. Durante os debates sobre o orçamento para o ano de 1914, o Congresso fixou os repasses da Inspetoria da Pesca em 396 contos de réis, apesar das reivindicações do deputado fluminense Carlos de Farias Souto pela dotação de 800 contos. Em outubro, o deputado carioca Nicanor Nascimento acusou o governo de ter gasto 1.180 contos de réis com a criação da Inspetoria da Pesca, quando o Congresso 
havia autorizado apenas 200 contos para o ano de 1913. O deputado fluminense Raul Fernandes, por sua vez, defendeu o governo mostrando erros de cálculo nas contas feitas por Nascimento (O Paíz, 04/10/1913).

Em dezembro, entrou em discussão na Câmara Federal a "emenda 18", uma autorização para o governo vender os peixes capturados que não fossem utilizados nas pesquisas da Inspetoria. O deputado do Distrito Federal, Irineu Machado, fez um discurso debochado, ironizando a existência da Inspetoria da Pesca, arrancando risos dos congressistas. Mais sério, o deputado pelo Estado do Rio de Janeiro, Maurício de Lacerda, apontou, logo em seguida, que a Câmara não podia receber essa emenda, por ser antirregimental. Já o deputado Luis Soares dos Santos, do Rio Grande do Sul, discordou, reafirmando a competência da Câmara em autorizar ou não a venda do pescado. A discussão foi, então, adiada (Correio da Manhã, 26/12/1913). Por fim, o Congresso Nacional, durante a votação do orçamento para o ano de 1914, extinguiu o gabinete de botânica da Inspetoria da Pesca como forma de conter despesas (Serviço de Informação e Divulgação, 1914a).

Nos primeiros meses de 1914, a Inspetoria da Pesca se encontrava sob forte pressão. Tanto a imprensa carioca, quanto uma grande parcela dos políticos viam pouca utilidade na existência do órgão, ao passo que a oposição ao governo Hermes se utilizava da inspetoria para atacar o governo. A primeira viagem de exploração ao mar com a embarcação José Bonifácio ocorreu entre os dias 6 e 9 de abril de 1914. Mesmo faltando instrumentos necessários às sondagens, tanto a Inspetoria, quanto o próprio MAIC esperavam ter sucesso em seus primeiros estudos sobre o plâncton na Baía de
Guanabara. De fato, essa viagem gerou a coleta de "grande quantidade de espécies de microplâncton" (Brasil, 1914, p. 108), que seria fundamental para a formação de coleções, classificação e publicações de artigos científicos nos anos posteriores. Mas o 'José Bonifácio' trouxe também consigo, segundo estimativas do MAIC, cerca de duas toneladas de peixes de espécies diversas que não seriam utilizados nas pesquisas (Brasil, 1914, p. 108).

A imagem do 'José Bonifácio' carregado com toneladas de peixes gerou reações imediatas e diversas na imprensa carioca, que, no geral, apontavam para o fracasso da expedição. O jornal Correio da Noite estampou em sua primeira página duas fotografias da expedição. Uma com os seus membros diante de centenas de peixes na proa do iate com a descrição: "o produto do primeiro lance". A segunda foto era do Dr. Gomes de Faria observando e separando espécies marinhas para a coleção do futuro Museu da Pesca. "Para o Museu da Inspetoria, trouxe o José Bonifácio um raro espécime de um crustáceo do gênero Libinia, colecionando-se também amostras de plâncton, de coral e de outros pequenos animais". Esse artigo forjava uma visão de sucesso da expedição, mas ressaltava, ao final, que na segunda vez que a rede foi lançada, os cientistas coletaram três toneladas de peixes, entre os quais pescadas, pescadinhas, corvinas e bagres (Correio da Noite, 14/04/1914).

Nas revistas de caricatura e humor, as estimativas oficiais que contavam duas toneladas de peixes se transformaram em quatro toneladas. A revista $O$ Rio $N u$ fez troça com o dito sucesso da expedição, ressaltando que "nada menos de 4 mil quilos de peixe vieram para o mercado. Quer isto dizer que os pescadores de águas turvas não puderam vender o seu peixe caro" (O Rio $N u, 18 / 04 / 1914)$. Já a 
revista $O$ Malho seguiu na mesma linha e publicou uma charge (Figura 1) ironizando o resultado da expedição, com a legenda: "Teremos agora peixe barato. A viagem do José Bonifácio, que fez uma experiência com aparelhos de pesca modernos, virá naturalmente baratear esse gênero de primeira necessidade. Até os peixões baixarão de preço..." (O Malho, 18/04/1914).

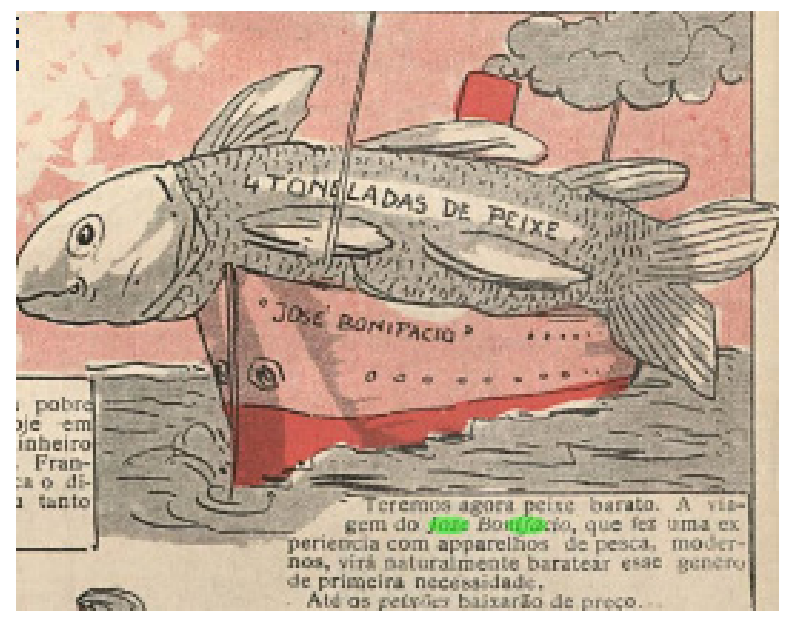

FIGURA 1 - Charge revista O Malho.

O resultado da viagem do 'José Bonifácio' não convenceu a imprensa, e as polêmicas sobre os gastos com a Inspetoria da Pesca continuaram. Em junho, o jornal $A$ Noite publicou um artigo denunciando que Alípio de Miranda Ribeiro havia pressionado a alfândega de modo a passar um contrabando de seda. Diante da polêmica, Miranda Ribeiro teve que se defender perante o ministro Pedro de Toledo e suas explicações foram publicadas no jornal O Paiz. Na defesa, o chefe da Inspetoria da Pesca apontou para o fato de ter encomendado diversos tipos de tecido, incluindo seda, da Société Suisse des Soies a Blutés de Genebra, por intermédio da empresa Moreno Borlido, para a confecção de redes e aparelhos especiais a serem usados pelo gabinete de zoologia na coleta de plânctons, ovos de peixes e areias finas. Esse material era necessário para os trabalhos do gabinete, que vinha dependendo do Instituto Oswaldo Cruz que, por seu turno, doava esses tecidos em pequenas quantidades para a inspetoria (O Paiz, 20/06/1914). Ao fim da polêmica, Ribeiro pediu demissão do cargo de chefe da Inspetoria, sendo substituído por Reynaldo Joaquim Ribeiro de Carvalho (Serviço de Informação e Divulgação, 1914b).

Não demorou para que o jornal Correio $d a$ Manhã voltasse novamente a sua artilharia contra o governo Hermes da Fonseca, utilizando-se dos custos da Inspetoria da Pesca. Em uma série de críticas ao número de empregados e aos gastos do MAIC, a Inspetoria ganhou destaque: "A Inspetoria da Pesca que é também uma daquelas criações nacionais que seriam inofensivas se não fosse o dinheiro que custa, tinha 58 empregados em 1913 e no ano corrente tem já 130" (Correio da Manhã, 13/08/1914). Os editores do periódico não perdoariam também a inauguração do Museu da Pesca, na Praia Vermelha, em 10 de novembro de 1914. Chamado de "museu da luxuosa Inspetoria da Pesca", o jornal qualificou a nova instituição de "aparelho de escoamento dos dinheiros públicos" sem muita razão de ser, já que as coleções poderiam ser alocadas, com menores custos financeiros, no Museu Nacional (Correio da Manhã, 11/11/1914).

A Inspetoria da Pesca sofreu com os cortes de gastos planejados no legislativo e mesmo pelo executivo em fins de 1914. A Grande Guerra (19141918) e a crise econômica deterioraram rapidamente as condições financeiras do Governo Federal, precipitando várias medidas de corte de despesas 
governamentais. Hermes da Fonseca, em uma série de medidas de contenção de gastos, ordenou que o iate José Bonifácio fosse retirado da responsabilidade do MAIC, passando para o Ministério da Marinha em novembro de 1914 (Correio da Manhã, 19/11/1914).

Na Câmara e no Senado Federal, os debates sobre a extinção de órgãos no MAIC avançaram. Em 5 de janeiro de 1915, a Inspetoria da Pesca foi extinta, junto com outros órgãos do Ministério, como a Superintendência de Defesa da Borracha. O Museu da Pesca, recentemente fundado, foi igualmente extinto e sua coleção entregue aos cuidados do Museu Nacional (Pombal Jr., 2002).

Com a extinção da Inspetoria da Pesca, a Estação de Pesca do Distrito Federal foi transformada em Estação de Biologia Marinha pelo decreto $n^{\circ}$ 11.507 de 04 de março de 1915. Sua finalidade era "o estudo, a investigação e a divulgação de todos os elementos do meio marinho capazes de aplicação às indústrias, atendendo a uma orientação científica e econômica" (Brasil, 1915, p. 123). Os objetivos da estação eram praticamente os mesmos dos gabinetes de zoologia e botânica da extinta Inspetoria da Pesca. Contudo, a Estação de Biologia Marinha teve vida ainda mais curta: foi extinta em 8 de janeiro de 1916 (Costa, 1916, p. 97).

\section{José Gomes de Faria e os estudos sobre plâncton na Inspetoria da Pesca}

O gabinete de zoologia, sob o comando do médico José Gomes de Faria, foi um dos setores mais ativos da Inspetoria da Pesca, classificando espécies e publicando trabalhos sobre plânctons da Baía de Guanabara. Gomes de Faria era um cientista em início de carreira. Ele formou-se em 1908 na Faculdade de Medicina do Rio de Janeiro e fez seus primeiros estudos sobre a vida marinha no âmbito da Inspetoria. Como resultado preliminar das suas investigações sobre as manchas cor de ferrugem na baía, em fins de julho de 1913, o médico escreveu a tese "Ensaio Sobre o Plankton, Seguido de Observações Sobre Occurrencia de Plankton Monotono, Causando Mortandade Entre os Peixes na Bahia do Rio de Janeiro". Com esse trabalho pioneiro, ele conquistou a vaga de livre docente na cadeira de História Natural Médica e Parasitologia da Faculdade de Medicina da Bahia, em 1914, ao lado dos médicos Arthur Neiva e Aristides Marques da Cunha (Correio da Manhã, 24/04/1914).

Sua tese trazia o estado da arte da nascente planctologia, mencionava as expedições científicas ao redor do mundo e as suas potenciais contribuições para o "problema econômico, social e industrial" ligado à pesca (Faria, 1914, p. 7). Na sua descrição histórica dos estudos sobre plâncton, Gomes de Faria destacou a importância do naturalista alemão Johann Friedrich (Fritz) Müller (1822-1897), colaborador de Charles Darwin, no estudo "indireto" do plâncton de Santa Catarina. Depois de Müller, seria "preciso dar um grande salto de quase meio século para encontrar mais alguma coisa na literatura brasileira" (Faria, 1914, p. 8). O naturalista Stanislas von Prowazek (1875-1915), que teria permanecido de 1908 a 1909 no Instituto Oswaldo Cruz, descreveu quase uma centena de protozoários de rios, baías e estuários no Rio de Janeiro e São Paulo até 1910. A sua obra foi ampliada por Aristides Marques da Cunha em 1913, que havia catalogado mais de 248 espécies (Cunha, 1913). Por fim, Gomes de Faria descreveu os métodos e petrechos utilizados na pesquisa, fez uma descrição taxonômica do plâncton, 
e ressaltou a relevância desses organismos sob os pontos de vista biológico, ecológico e econômico.

Gomes de Faria descreveu, pela primeira vez na América do Sul, o fenômeno da "água do monte", observado em junho de 1913 na baía da Guanabara. Ele propôs que esse fenômeno resultava da proliferação inexplicada dos plânctons peridíneos da espécie ora identificada como Glenodinium trochoideum $^{5}$. Atualmente, associa-se a explosão populacional desses organismos à eutrofização antropogênica, que é o aumento na quantidade de nutrientes na água, e sua consequente degradação, por indução humana (Moncheva et al., 2001).

A fundação do Museu da Pesca, em novembro de 1914, sob a direção do próprio Gomes de Faria, foi outro ponto alto da Inspetoria da Pesca. O gabinete de zoologia foi o maior responsável pela abertura do museu, com aproximadamente 600 espécies de animais marinhos, tornando-se a segunda maior coleção desse gênero no Brasil (Serviço de Informação e Divulgação, 1914a). Após a primeira missão do 'José Bonifácio', um grande volume de material foi coletado e catalogado, proporcionando a abertura de duas sessões de animais marinhos vertebrados e invertebrados (Correio da Manhã, 11/11/1914). A relevância desse trabalho não parecia ser de todo ignorado pela imprensa e menos ainda por médicos e cientistas. Apesar das fortes críticas feitas pelo jornal Correio $d a$ Manhã, a própria redação do periódico doou para o instituto uma fotografia de uma onda atingindo a Avenida Beira Mar, por ocasião das ressacas de março de 1913 (O Paíz, 01/04/1913). O Instituto
Oswaldo Cruz, que contribuiu com material para a realização de pesquisas no âmbito do gabinete de zoologia da Inspetoria da Pesca, também colaborou com o acervo. O próprio Oswaldo Cruz doou uma coleção de peixes do rio Amazonas para o museu (O Paíz, 01/04/1913). No entanto, a turbulência política e econômica ajudou nas desqualificações da instituição e nos cortes de investimento financeiro para as pesquisas no âmbito da Inspetoria da Pesca.

Com o fim da Inspetoria da Pesca e o fracasso da Estação de Biologia Marinha, José Gomes de Faria trabalhou no Instituto Oswaldo Cruz, onde conseguiu continuar as pesquisas iniciadas em 1913. Em parceria com os médicos Aristides Marques da Cunha e Olímpio da Fonseca, Gomes de Faria realizaria uma expedição pelo mar do Rio de Janeiro e outras três viagens até o Mar del Prata, na Argentina, entre os anos de 1916 e 1918. Dessas expedições, os médicos publicaram na revista Memórias do Instituto Oswaldo Cruz os artigos “O Microplâncton da Bahia do Rio de Janeiro” (1917) e "O Microplâncton das Costas Meridionais do Brasil" (1918). O primeiro foi produto da parceria entre Gomes de Faria e Marques da Cunha, e o segundo, entre Olímpio Fonseca e Marques da Cunha.

Em "O Microplâncton da Bahia do Rio de Janeiro", Gomes de Faria e Cunha enumeram as espécies de plâncton já descritas para a baía da Guanabara, detalhando as circunstâncias em que os espécimes foram encontrados, a frequência de ocorrência, suas características morfológicas e por quem foi descrito inicialmente, dentre outras informações. Em alguns casos, os autores se apro- 
fundam em discussões taxonômicas, fornecendo novas contribuições quanto às formas de classificar as espécies estudadas (Faria \& Cunha, 1917). Em "O Microplâncton das Costas Meridionais do Brasil", Fonseca e Cunha ressaltam a importância dos trabalhos de Gomes de Faria no pioneirismo das observações sistemáticas no Brasil. Nesse trabalho, os autores complementam o trabalho de caracterização do plâncton, abrangendo novas regiões meridionais do País e, inclusive, da costa argentina, e relatam a ocorrência de um bloom planctônico na baía de Paranaguá, no estado do Paraná (Cunha \& Fonseca, 1918).

O que essas parcerias e estudos indicam é que, apesar das controvérsias políticas e da vida efêmera do Instituto da Pesca, a instituição ajudou na promoção das primeiras iniciativas de estudos sobre plâncton na costa do Rio de Janeiro, gerando coleções, trabalhos e, principalmente, pequenas redes de cientistas interessados nos estudos planctônicos na costa brasileira.

A parceria entre José Gomes de Faria e Aristides Marques da Cunha continuaria na década de 1920, em termos de pesquisas sobre a vida marinha, trabalhando principalmente na classificação de protozoários do mar (Faria et al., 1922). Importante ressaltar também os estudos sobre plânctons realizados quase na mesma época de atuação da Inspetoria da Pesca, pelo jesuíta alemão Carlos Zimmermann. Embora ele não tivesse ligação com os cientistas da Inspetoria, é considerado um dos primeiros especialistas em diatomáceas no País e descreveu 49 novas espécies dos rios, lagos e estuários no Brasil (Gomes et al, 2012). Seus trabalhos com diatomáceas se encerraram em 1919, quando ele passou a se dedicar a atividades de ensino na cidade de Barreiras, na Bahia.
Há também o caso de dois nomes ilustres que fizeram parte dos quadros da Inspetoria da Pesca: Francisco Carlos Hoehne e Alípio de Miranda Ribeiro. Hoehne se mudou para São Paulo em 1917, dedicou-se à ampliação do conhecimento botânico e exerceu um papel fundamental na reorganização de instituições científicas em São Paulo entre os anos de 1920 a 1940 (Molina, 2016). Ele é considerado, atualmente, um dos principais cientistas a propagar ideias de conservação ambiental no Brasil, no início do século XX (Franco \& Drummond, 2005, 2007, 2012; Molina \& Norder, 2014). Miranda Ribeiro, por outro lado, já era uma das maiores referências na zoologia brasileira do período (Lopez, 2009). Depois da sua saída da Inspetoria da Pesca, foi membro fundador da Sociedade Brasileira de Ciências e continuou na produção de uma vasta bibliografia sobre vertebrados e invertebrados da fauna brasileira, e também da fauna marinha, embora não tenha se dedicado a pesquisas sobre o plâncton (Pombal Jr., 2002).

\section{Considerações finais}

A turbulenta trajetória da Inspetoria da Pesca e a sua dissolução formam uma história que congrega diversos agentes e instituições. Ministério da Agricultura, Indústria e Comércio, pescadores, cientistas em início de carreira e outros já reconhecidos em suas áreas de atuação, políticos, plânctons, órgãos da imprensa carioca - críticos ou não do Presidente Hermes da Fonseca -, dentre outros. Pensada pelo MAIC como uma instituição que realizaria pesquisas científicas a fim de organizar e incentivar uma indústria pesqueira no Brasil, a Inspetoria da Pesca representou uma importante iniciativa, que foi 
pouco compreendida no âmbito das tomadas de decisão no legislativo brasileiro e na própria imprensa carioca. Foi também uma iniciativa arrebatada por uma crise econômica, que potencializou a incompreensão e gerou possibilidades para aqueles que buscavam formas de criticar o Executivo Federal. Os custos de formação e manutenção da Inspetoria foram encarados como uma boa oportunidade para a oposição a Hermes da Fonseca na imprensa, que usou esses gastos para denunciar supostas irregularidades, sejam no âmbito do poder executivo ou do próprio MAIC.

Por outro lado, um bloom planctônico na Baía de Guanabara, em fins de julho de 1913, ajudou na conformação da maior parte dos interesses e esforços de pesquisa do gabinete de zoologia da Inspetoria da Pesca. O fenômeno "águas do monte" surpreendeu o zoólogo José Gomes de Faria e os demais cientistas da Inspetoria, tornando mais notória a utilidade da nascente planctologia a partir de uma relação direta entre plânctons e economia pesqueira. Ainda que os riscos para a saúde pública não fossem de todo evidentes, o fenômeno do bloom de peridíneos na Baía de Guanabara com a consequente mortalidade em massa de peixes era encarado como um problema concreto para uma futura indústria da pesca. Essa situação resultou nas primeiras expedições ao mar, realizadas por cientistas brasileiros, com a finalidade de estudar os plânctons na costa brasileira. Mesmo com o fim das atividades da Inspetoria da Pesca, as parcerias iniciadas no período de existência da instituição permaneceram dando fôlego a expedições posteriores, sendo importante para cientistas, como José Gomes de Faria, no seu início de carreira.

A Inspetoria da Pesca foi um órgão do Ministério da Agricultura, Indústria e Comércio que teve vida efêmera devido aos (des)interesses políticos, associados à crise econômica e às oposições ao governo Hermes da Fonseca. Essas condições favoreceram o fato de que a maior parte das atribuições do órgão não saíssem do papel ou fossem parcialmente realizadas. Contudo, as circunstâncias ocorridas no ambiente aquático da Baía de Guanabara, nos primeiros meses de existência da Inspetoria, levaram o gabinete de zoologia desse órgão a tornar-se responsável pelos primeiros estudos sobre plânctons no Brasil. Esses estudos ajudaram na conformação de um pequeno grupo interessado em estudos planctológicos, no momento que essa especialidade emergia com mais força na Europa. Assim, a Inspetoria da Pesca, com suas largas atribuições, existiu principalmente imersa entre plânctons e controvérsias políticas, contribuindo para os primórdios da planctologia no Brasil, apesar de sua curta existência.

\section{Agradecimentos}

O presente trabalho foi realizado com apoio da Coordenação de Aperfeiçoamento de Pessoal de Nível Superior - Brasil (CAPES) - Código de Financiamento 001

\section{Referências}

Archela, R. S.; Archela, E. Síntese cronológica da cartografia no Brasil. Portal da Cartografia, 1(1), 93-110, 2008. Disponível em: <http://www.educadores.diaadia.pr.gov. br/arquivos/File/2010/artigos_teses/teses_geografia2008/ artigouelroseliarchekaedison.pdf $>$. Acesso em: abr. 2017.

Bhering, M. J.; Maio, M. C. Ciência, positivismo e agricultura: uma análise do Ministério da Agricultura, Indústria e 
Comércio na Primeira República. Varia História, 27(46), 689-709, 2011. doi: 10.1590/S0104-87752011000200015

Brasil, Ministério da Agricultura, Indústria e Comércio. Relatório apresentado ao Presidente da República dos Estados Unidos do Brasil pelo ministro de estado dos negócios da agricultura, indústria e comércio Dr. Pedro de Toledo no ano de 1911. Rio de Janeiro: Oficinas da Diretoria Geral de Estatística, 1911. Disponível em: <http://www-apps.crl. edu/brazil/ministerial/agricultura>. Acesso em: jan. 2017.

Brasil, Ministério da Agricultura, Indústria e Comércio. Relatório dos anos de 1911 e 1912 apresentado ao Presidente da República dos Estados Unidos do Brasil pelo ministro Dr. Pedro de Toledo. Rio de Janeiro: Imprensa Nacional, 1912. Disponível em: $<$ http://www-apps.crl.edu/brazil/ministerial/ agricultura $>$. Acesso em: jan. 2017.

Brasil, Ministério da Agricultura, Indústria e Comércio. Relatório do ano de 1913 apresentado ao Presidente da República dos Estados Unidos do Brasil pelo ministro Dr. Manoel Edwiges de Queiroz Vieira. Rio de Janeiro: Imprensa Nacional, 1914. Disponível em: <http://www-apps.crl. edu/brazil/ministerial/agricultura $>$. Acesso em: jan. 2017.

Brasil, Ministério da Agricultura, Indústria e Comércio. Relatório do ano de 1914 apresentado ao Presidente da República dos Estados Unidos do Brasil pelo ministro Dr. José Rufino Bezerra Cavalcanti. Rio de Janeiro: Imprensa Nacional, 1915. Disponível em: $<$ http://www-apps.crl.edu/ brazil/ministerial/agricultura $>$. Acesso em: jan. 2017.

Brunner, B. The ocean at home: an illustrated history of the aquarium. New York: Princeton University Press, 2005.

Carpine-Lancre, J. Mathurin méheut et le musée océanographique. Monaco: Musée Océanographique, 1994.

Correio da Manhã. Editais. 14 agosto, 9, 1913.

Correio da Manhã. Inspetoria da Pesca. 14 julho, 7, 1913.

Correio da Manhã. O que dizem os telegramas. 03 agosto, $2,1913$.

Correio da Manhã. Os orçamentos. 26 dezembro, 3, 1913.

Correio da Manhã. Quem vai pescar no Iate José Bonifácio? Há quem afirme que é o marechal. 20 setembro, 3, 1913.

Correio da Manhã. Reuniu-se ontem em despacho coletivo o Ministério. 15 fevereiro, 3, 1913.

Correio da Manhã. Tópicos e Notícias. 03 setembro, 1, 1913.

Correio da Manhã. Faculdade de Medicina: os novos livres docentes. 24 abril, 3, 1914.

Correio da Manhã. Informações valiosas: o que vai pelos ministérios. 13 agosto, 2, 1914.

Correio da Manhã. Medidas importantes tomadas pelo governo. 19 novembro, 3, 1914.

Correio da Manhã. Os melhoramentos do governo de S. M. Dudú I: mais uma para a pesca dos dinheiros da nação. 11 novembro, 3, 1914.

Correio da Noite. Entre nós: Viagem do José Bonifácio. 14 abril, 1, 1914.

Costa, A. A indústria da pesca. Boletim do Ministério da Agricultura, Indústria e Comércio, 5(2) 93-102, 1916.

Cunha, A. M. da. Contribuição para o conhecimento da fauna de protozoários do Brasil. Memórias do Instituto Oswaldo Cruz, 5(2), 101-122, 1913. doi: 10.1590/S007402761913000200001.

Cunha, A. M. da; Fonseca, O. O microplancton das costas meridionais do Brasil. Memórias do Instituto Oswaldo Cruz, 10(2), 99-103, 1918. Disponível em: <http://www.scielo.br/ pdf/mioc/v10n2/tomo10(f2)_99-103.pdf>.

Damkaer, D. M.; Mrozek-Dahl, T. The Plankton-Expedition and the Copepod Studies of Friedrich and Maria Dahl. In: Sears, M.; Merriman, D. Oceanography: The Past. New York-Heidelberg-Berlin: Springer-Verlag, 1980. p. 462-473.

Deacon, M. Scientists and the Sea, 1650-1900. A Study of Marine Science. London and New York: Academic Press, 1971.

Faria, J. G. de; Cunha, A. M. da; Pinto, C. Estudos sobre Protozoarios do Mar. Memórias do Instituto Oswaldo Cruz, 15(1), 186-208, 1922. doi: 10.1590/S007402761922000200013

Faria, J. G. de; Cunha, A. M. da. Estudos sobre o Microplancton da baía do Rio de Janeiro e suas imediações. Memórias do Instituto Oswaldo Cruz, 9(1), 68-93, 1917. doi: 10.1590/S0074-02761917000100003 
Faria, J. G. de. Um ensaio sobre o plâncton, seguido de observações sobre ocorrência de plâncton monotono, causando mortandade entre os peixes na Baía do Rio de Janeiro. Trabalho apresentado a Faculdade de Medicina do Rio de Janeiro, para a obtenção do título de docente livre. Rio de Janeiro: Typ. Do Jornal do Commercio de Rodrigues \& C., 1914.

Franco, J. L. A.; Drummond, J. A. Frederico Carlos Hoehne: A Atualidade de um Pioneiro no Campo da Proteção à Natureza no Brasil. Ambiente e Sociedade, 8(1), 141-166, 2005. doi: 10.1590/S1414-753X2005000100009

Franco, J. L. A.; Drummond, J. A. Frederico Carlos Hoehne: Viagens e Orquídeas. História Revista (UFG), 12, 317-351, 2007. doi: https://doi.org/10.5216/hr.v12i2.5473

Franco, J. L. A.; Drummond, J. A. Frederico Carlos Hoehne: viagens, ciência e proteção à natureza. Orquidario, 26, 41-50, 2012.

García, S. V. Commercial fishing and the study of marine fauna in Argentina, 1890-1930. História, Saúde, Ciências - Manguinhos, 21(3), 1-18, 2014. doi: 10.1590/S010459702014000300003

Gomes, D. F.; Caldas, O.; Silva, E. M. da; Gell, P. A.; Williams, D. M. Father Zimmermann (1871-1950): the first Brazilian diatomist, Diatom Research, 27(3), 1-12, 2012. doi: 10.1080/0269249X.2012.698646

Grohmann, P. A., Quijada, A. L., Calder, D. R. Nineteenth and Early Twentieth Century Expeditions: Their Explorations. In: Brazil, With the First Contributions to Knowledge of the Hydrozoa. Breviora, 550, 1-25, 2016. doi: 10.3099/ MCZ24.1

Jardim, M. E., Peres, I. M.; Ré, P. B.; Costa, F. M. A prática oceanográfica e a coleção iconográfica do rei dom Carlos I. História, Ciências, Saúde - Manguinhos, 21(3), 883-909, 2014. doi: 10.1590/S0104-59702014000300006

Jornal do Commercio de Manáos. O governo do estado oficia ao ministro da viação e obras públicas sobre a 'Amazon Wireless.' 16 abril, 1, 1912.

Kisling Jr.; V. N. Zoo and aquarium history: ancient animal collections to zoological gardens. Boca Raton: CRC Press, 2000 .
Kretschmann, J.; Elbrachter, M.; Zinssmeister, C.; Soehner, S.;Kirsch, M.; Kusber, W.-H.; Gottschling, M. Taxonomic clarification of the dinophyte Peridinium acuminatum Ehrenb., $\equiv$ Scrippsiella acuminata, comb. nov. (Thoracosphaeraceae, Peridiniales). Phytotaxa, 220(3), 239-256, 2015. doi: 10.11646/phytotaxa.220.3.3

Lima, N. T. Um Sertão Chamado Brasil: Intelectuais e Representação Geográfica da Identidade Nacional. Rio de Janeiro: Revan/IUPERJ/UCAM, 1999.

Longo, L. de L.; Amado Filho, G. M. O conhecimento da fauna marinha bentônica brasileira através dos tempos. História, Ciências, Saúde-Manguinhos, 21(3), 995-1010, 2014. doi: 10.1590/S0104-59702014000300011

Lopes, M. M.; Podgorny, I. Entre mares e continentes: aspectos da trajetória científica de Hermann von Ihering, 1850-1930. História, Ciências, Saúde-Manguinhos, 21(3), 809-826, 2014. doi: 10.1590/S0104-59702014000300002.

Lopez, M. R. Miranda Ribeiro: um zoólogo evolucionista nos primeiros anos da República (1894-1938). Tese (Doutorado) Fundação Oswaldo Cruz, Programa de Pós-Graduação em História das Ciências e da Saúde, 2009.

Martínez, A. "A souvenir of undersea landscapes:” underwater photography and the limits of photographic visibility, 1890-1910. História, Ciências, Saúde - Manguinhos, Rio de Janeiro, 21(3), Não paginado, 2014. doi: 10.1590/S010459702014000300013

Mello, V. P. S. "O Agricutor Progressista”: ciência e proteção à natureza nas revistas do Ministério da Agricultura, Indústria e Comércio (1837-1932), Dissertação (Mestrado) - Fundação Oswaldo Cruz, Programa de Pós-Graduação em História das Ciências e da Saúde, 2012.

Molina, A. A. Frederico Carlos Hoehne (1882-1959) e a flora medicinal brasileira: a pesquisa botânica na cidade de São Paulo no início do século XX. Dissertação (Mestrado) - Universidade Estadual Paulista, Faculdade de Ciências Agronômicas, 2016.

Molina, A. A.; Norder, L. A. C. A contribuição de F. C. Hoehne (1882-1959) para o pensamento agroambiental brasileiro. Revista Brasileira de História da Ciência, 7(1), 70-80, 2014. Disponível em: <http://www.sbhc.org.br/ revistahistoria/view?ID_REVISTA_HISTORIA=51\&im- 
pressao $>$

Moncheva, S.; Gotsis-Skretas, O.; Pagou, K.; Krastev, A. Phytoplankton blooms in Black Sea and Mediterranean coastal ecosystems subjected to anthropogenic eutrophication: similarities and differences. Estuarine, Coastal and Shelf Science, 53(3), 281-295, 2001. doi: 10.1006/ecss.2001.0767

O Malho. Salada da Semana. 18 abril, 35, 1914.

O Paíz. Congresso Nacional. 04 outubro, 7, 1913.

O Paíz. Crônica dos fatos. 01 abril, 6, 1913.

O Paíz. Ministério da Agricultura, Indústria e Comércio. 04 agosto, 9, 1913.

O Paíz. O pretenso contrabando das sedas. 20 junho, 2, 1914.

O Rio Nu. Trepações. 18 abril, 6, 1914.

Paiva, M. P. Instituições de Pesquisas Marinhas do Brasil. IBAMA, Brasília, 1996.

Pombal Jr. J. R. Nota Biográfica sobre Alípio de Miranda Ribeiro (1874-1939). Revista Brasileira de Zoologia, 19(3), 935-939, 2002. doi: 10.1590/S0101-81752002000300030

Rollo, M. F.; Queiroz, M. I.; Brandão, T. O mar como ciência: instituições e estratégias da investigação sobre o mar em Portugal no século XX (da Primeira República à democracia). História, Ciências, Saúde-Manguinhos, 21(3), 847-865, 2014. doi: 10.1590/S0104-59702014000300004

Sá, D. M. de; Sá, M. R. de; Lima, N. T. Telégrafos e inventário do território no Brasil: as atividades científicas da Comissão Rondon (1907-1915). História, Ciências e Saúde - Manguinhos, 15(3), 779-810, 2008. doi: 10.1590/ S0104-59702008000300011
Salgado, M. de M.; Marandino, M. O mar no museu: um olhar sobre a educação nos aquários. História, Ciências, Saúde-Manguinhos, 21(3), 867-882, 2014. doi: 10.1590/ S0104-59702014000300005

Sardet, C. Plankton: wonders of the drifting world. Chicago and London: The University Chicago Press, 2015.

Serviço de Informação e Divulgação. O Regulamento da Pesca. Boletim do Ministério da Agricultura, Indústria e Comércio, 1(3), 144-147, 1912.

Serviço de Informação e Divulgação. Inspetoria da Pesca. Boletim do Ministério da Agricultura, Indústria e Comércio, 3(4) 159-162, 1914a.

Serviço de Informação e Divulgação. Leis, portarias e atos do governo. Boletim do Ministério da Agricultura, Indústria e Comércio, 3(4), 1-17, 1914b.

Shick, J. M. Toward an aesthetic marine biology. Art Journal, 67(4), 62-86, 2008. doi: 10.1080/00043249.2008.10791327

Varela, A. G. O Instituto Oceanográfico da Universidade de São Paulo: um capítulo do processo de emergência e consolidação das ciências oceanográficas no Brasil, 1946-1969. História, Ciências e Saúde - Manguinhos, 21(3), 951-969, 2014. doi: 10.1590/S0104-59702014000300009.

Vital, A. V.; Tejerina-Garro, F. L. O incentivo à pesca comercial de Arapaima gigas (pirarucu) do rio Araguaia (Brasil central) na revista "A Informação Goyana" (1917-1935). Boletim do Museu Paraense Emílio Goeldi. Ciências Humanas, 13(1), 159-174, 2018. doi: 10.1590/1981.81222018000100009 